\title{
Light-modulated Antennae Acclimation in the Cyanobacterium Anacystis nidulans: Effects of Transcriptional and Translational Inhibitors
}

\author{
By S. ROGER KALLA, ${ }^{1}$ * ANDERS LÖNNEBORG,${ }^{2}$ GUNNAR ÖQUIST ${ }^{2}$ \\ AND PETTER GUSTAFSSON ${ }^{1}$ \\ Institute of Cell and Molecular Biology ${ }^{1}$ and Plant Physiology ${ }^{2}$, University of Umeå, \\ S-901 87 Umeå, Sweden
}

(Received 30 April 1986)

\begin{abstract}
The effect of transcriptional and translational inhibitors on growth and on the light acclimation of the photosynthesis antennae of Anacystis nidulans was examined after a shift from white incandescent light $\left(300 \mu \mathrm{E} \mathrm{s}^{-1} \mathrm{~m}^{-2}\right)$ to red light $\left(15 \mu \mathrm{E} \mathrm{s}^{-1} \mathrm{~m}^{-2}\right)$. Addition of antibiotics that inhibit transcription (rifampicin) or translation (streptomycin, chloramphenicol and kanamycin) immediately blocked cell growth, and RNA and protein synthesis, when added either early or later after the light shift. The ratio of phycocyanin to chlorophyll $a$ stayed constant. Addition of the antibiotics shortly after the shift also immediately blocked the increase in the ratios of phycocyanin and chlorophyll $a$ to cell mass, whereas later addition resulted in decreases of about $50 \%$ and 12 to $30 \%$ in these ratios with rifampicin and streptomycin, respectively. No changes in pigment content were found when the antibiotics were added during steady state conditions with white or red light. The results show that both phycocyanin and chlorophyll $a$ light acclimations are immediately and completely blocked by the addition of both transcriptional and translational inhibitors. We also propose that the light antennae may exist in an unstable form in the course of the acclimation process.
\end{abstract}

\section{INTRODUCTION}

Anacystis nidulans is a unicellular obligate photoautotrophic cyanobacterium (Stanier \& Cohen-Bazire, 1977). It uses light as its only energy source, which implies that effective harvesting of light quanta is essential for optimal growth. Acclimation to different light environments by cyanobacteria is characterized by alterations in the photosynthetic apparatus, especially pronounced in the light-harvesting phycobilisomes (Raps et al., 1983; Yamanaka \& Glazer, 1981).

The phycobilisome of $A$. nidulans contains the chromoproteins C-phycocyanin $\left(\lambda_{\max } 625 \mathrm{~nm}\right)$, allophycocyanin $\left(\lambda_{\max } 650 \mathrm{~nm}\right)$ and allophycocyanin $B\left(\lambda_{\max } 670 \mathrm{~nm}\right)$, and also at least four nonpigmented polypeptides of molecular mass 75, 33, 30 and $27 \mathrm{kDa}$ (Gantt, 1979; Glazer, 1982; Lundell et al., 1981). Phycocyanin is contained within the rods of the phycobilisome whereas allophycocyanin and allophycocyanin B are located in the phycobilisome core (Glazer et al., 1979). The phycobiliprotein compositions of $A$. nidulans and other cyanobacteria show both quantitative and qualitative variations in response to culture conditions and light quality (Bogorad, 1975; Glazer, 1981; Myers et al., 1978). High levels of phycocyanin are favoured by high temperature, high $\mathrm{CO}_{2}$ concentrations and low light intensities (Eley, 1971; Goedheer, 1976; Öquist, 1974). Examination of phycobilisomes of $A$. nidulans by electron microscopy revealed that the length of the rods decreases with increasing light intensities during growth, the decrease being accompanied by the disappearance of the 33 and $30 \mathrm{kDa}$ polypeptides from the phycobilisome (Yamanaka \& Glazer, 1981). Lönneborg et al. (1985) examined growth and light-

Abbreviations: HW-light, high intensity white light; LR-light, low intensity red light. 
harvesting antennae content in $\boldsymbol{A}$. nidulans under high intensity white (HW-) light and after a shift to low intensity red (LR-) light. Cell growth ceased for $10 \mathrm{~h}$ after the light shift and then recommenced at a new steady state with a doubling time 10 times slower than that under $\mathrm{HW}$ light. The light shift caused an immediate change in the phycocyanin to chlorophyll $a$ ratio, which approached a new steady state value about $50 \mathrm{~h}$ after the shift, as well as immediate changes in the phycocyanin to cell mass and chlorophyll $a$ to cell mass ratios. The immediate increase in the phycocyanin content after the shift from HW-light to LR-light coincided with the synthesis of the 33 and $30 \mathrm{kDa}$ polypeptides typically found in the phycobilisomes from low light conditions (Yamanaka \& Glazer, 1981), suggesting an efficient light-mediated regulatory mechanism.

The synthesis of RNA and protein in cyanobacteria is inhibited by antibiotics known for this effect in other prokaryotic organisms. Streptolydigin blocked RNA synthesis in $A$. nidulans immediately (Doolittle, 1972) and rifampicin and chloramphenicol inhibited the synthesis of phycoerythrin in Fremyella diplosiphon within 1 to $2 \mathrm{~h}$ of addition, following a shift from red to green light (Gendel et al., 1979).

In this communication, we report the effects of transcriptional and translational inhibitors on the acclimation of the antennae of $A$. nidulans after a shift from HW-light to LR-light.

\section{METHODS}

Strain and culture conditions. Anacystis nidulans UTEX 625 (Synechococcus PCC 6301) (Rippka et al., 1979), was grown in the medium described by Siva et al. (1977) except that Fe- $N$-hydroxyl-EDTA was replaced by $14.4 \mu \mathrm{M}$ $\mathrm{FeCl}_{3} .6 \mathrm{H}_{2} \mathrm{O}$ and $65 \mu \mathrm{M}$-EDTA. The cells were grown with shaking in $200 \mathrm{ml}$ rectangular tissue flasks at $39^{\circ} \mathrm{C}$ with an atmosphere of $2 \%(\mathrm{v} / \mathrm{v}) \mathrm{CO}_{2}$ in air as described by Öquist (1974). They were kept in the exponential phase of growth at $\mathrm{OD}_{750}<0.5$ by stepwise dilution with prewarmed medium (Lönneborg et al., 1985).

HW-light was provided by two incandescent lamps placed over the culture. LR-light was provided by placing a red plexiglass filter and a blue celluloid filter between the lamps and the culture. The heat produced by the lamps was reduced by water filters under both light regimes. The quantum fluxes were 300 and $15 \mu \mathrm{E} \mathrm{s}^{-1} \mathrm{~m}^{-2}$ for $\mathrm{HW}$ light and LR-light, respectively (Lönneborg et al., 1985).

Spectroscopic measurements. $\mathrm{OD}_{750}$ was measured in a Zeiss spectrophotometer PM4 QIII equipped with Multiblank 171 and Multilog 311 from Optilab and was taken as a measure of cell mass (Lönneborg et al., 1985). Absorption spectra were measured on a Shimadzu MPS-50L spectrophotometer between 600 and $750 \mathrm{~nm}$. From these spectra the amount of phycocyanin $\left(A_{625}\right)$ and chlorophyll $a\left(A_{678}\right)$ relative to $\mathrm{OD}_{750}$ and the $A_{625} / A_{678}$ were estimated as described by Myers et al. (1978) and Lönneborg et al. (1985).

RNA and protein measurements. RNA was measured by the orcinol method (Schneider, 1945) and protein by the Lowry method.

\section{RESULTS}

\section{Effects of transcriptional and translational inhibitors on growth, and on RNA and protein synthesis}

In preliminary experiments (results not shown), growth and RNA synthesis in A. nidulans were studied after the addition of rifampicin. Cells acclimated to HW-light were grown to an $\mathrm{OD}_{750}$ of 0.3 . The culture was then divided and to one sample rifampicin was added (final concentration of $200 \mu \mathrm{g} \mathrm{ml}^{-1}$ ). Both cultures were reincubated under $\mathrm{HW}$-light and samples were withdrawn periodically to measure total RNA content. Both growth and RNA synthesis were blocked immediately and completely in the presence of rifampicin, suggesting effective shut off of transcription as shown before for other cyanobacteria (Doolittle, 1972; Gendel et al., 1979). No cell lysis or swelling was observed up to $5 \mathrm{~h}$ implying that $\mathrm{OD}_{750}$ can be used as a reliable indicator of growth in the presence of rifampicin. Furthermore, there was no significant decrease of total RNA up to $5 \mathrm{~h}$.

A similar experiment under identical growth conditions was done in the presence of streptomycin (final concentration $100 \mu \mathrm{g} \mathrm{ml}^{-1}$ ). Again growth ceased immediately after the addition of the antibiotic, implying inhibition at the translational level as shown before (Gendel et al., 1979). No cell lysis or swelling was observed, nor did total protein levels decline up to $5 \mathrm{~h}$ after addition of streptomycin. The antibiotics kanamycin and chloramphenicol (final concentrations $200 \mu \mathrm{g} \mathrm{ml}^{-1}$ ) gave identical results (data not shown). 


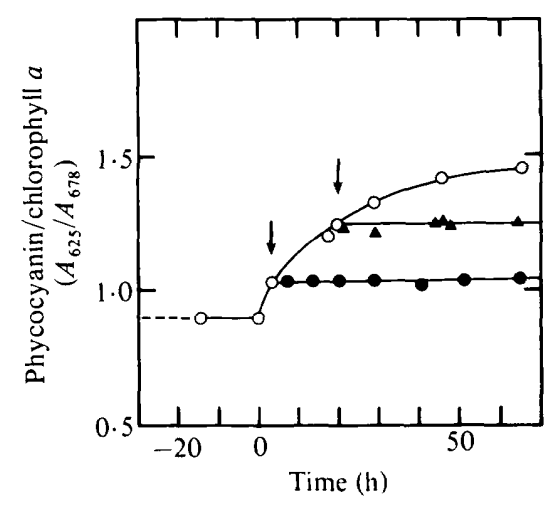

Fig. 1. Effect of rifampicin on the acclimation of phycocyanin. A culture of $A$. nidulans was grown under $\mathrm{HW}$-light. At time 0, the culture was divided and shifted to LR-light. Rifampicin $\left(200 \mu \mathrm{g} \mathrm{ml}^{-1}\right)$ was added (arrows) $2.5 \mathrm{~h} \mathrm{(O)}$ or $20 \mathrm{~h}(\mathbf{\Delta})$ after the light shift. O, Control culture without rifampicin.

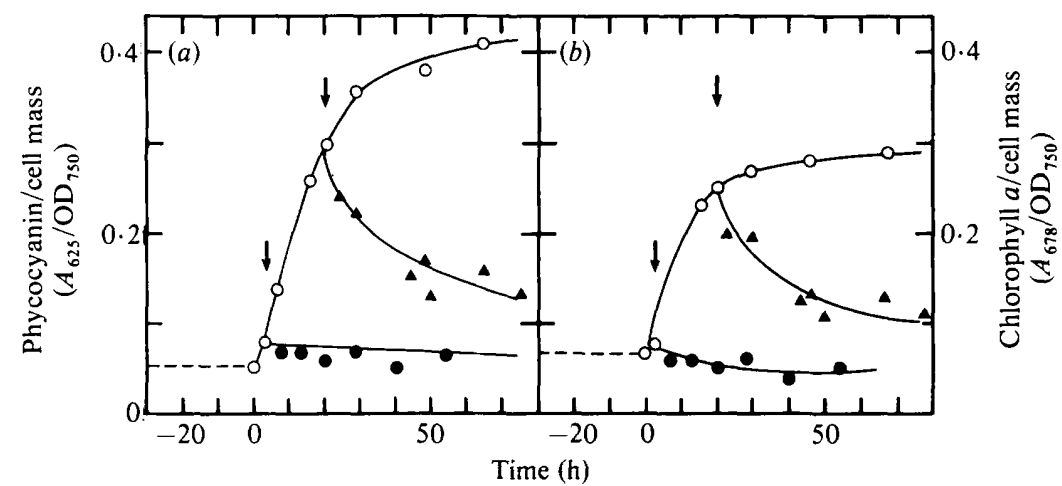

Fig. 2. Effect of rifampicin on antennae acclimation expressed as phycocyanin/cell mass ratio $(a)$ and chlorophyll $a /$ cell mass ratio $(b)$. Symbols as in Fig. 1.

\section{Effect of a transcriptional inhibitor on antennae acclimation after a light shift}

The effect of rifampicin was also examined following a shift from HW-light to LR-light. Rifampicin $\left(200 \mu \mathrm{g} \mathrm{ml}^{-1}\right)$ was added 2.5 and $20 \mathrm{~h}$ after the shift: phycocyanin and chlorophyll $a$ acclimation stopped immediately (Figs 1 and 2) and $A_{625} / A_{678}$ stayed constant for at least $50 \mathrm{~h}$ irrespective of the time of addition of the antibiotic (Fig. 1). However, when light antennae acclimation is presented as $A_{625} / \mathrm{OD}_{750}$ and $A_{678} / \mathrm{OD}_{750}$ the ratios stayed constant only when rifampicin was added $2.5 \mathrm{~h}$ after the shift, and decreased substantially (about $50 \%$ compared to the ratios observed at the moment of addition) when the antibiotic was added $20 \mathrm{~h}$ after the light shift (Fig. 2). These results demonstrate that a block in transcription inhibits the lightmodulated antennae acclimation. The loss of phycocyanin and chlorophyll $a$ absorbing complexes, suggested by the lower $A_{625} / \mathrm{OD}_{750}$ and $A_{678} / \mathrm{OD}_{750}$ ratios (Fig. 2) when rifampicin was added $20 \mathrm{~h}$ after the shift, indicates that the light antennae require continuous transcription during the acclimation process in order to reach the levels observed in the control without rifampicin (Fig. 2), and also suggests that the newly synthesized antennae disappear due to proteolytic or non-enzymic degradation.

\section{Effect of translational inhibitors on antennae acclimation after a light shift}

When streptomycin $\left(100 \mu \mathrm{g} \mathrm{ml}^{-1}\right)$ was added 2.5 and $19 \mathrm{~h}$ after a shift from HW-light to LRlight, the results were quantitatively similar to those obtained with rifampicin except that the 


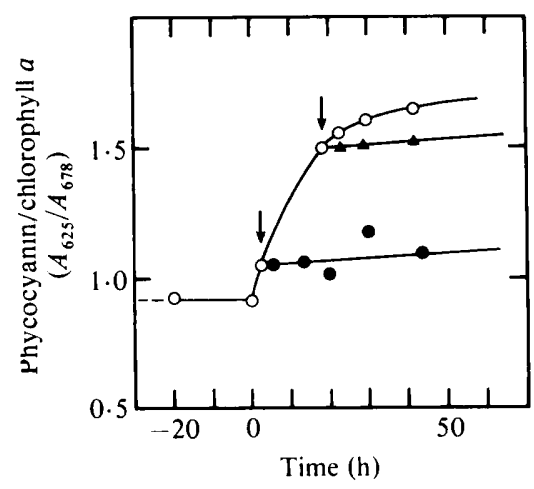

Fig. 3. Effect of streptomycin on phycocyanin acclimation after a shift from HW-light to LR-light. Streptomycin $\left(200 \mu \mathrm{g} \mathrm{ml}^{-1}\right)$ was added (arrows) $2.5 \mathrm{~h}(O)$ or $19 \mathrm{~h}(\mathbf{A})$ after the shift. $O$, Control culture without streptomycin.

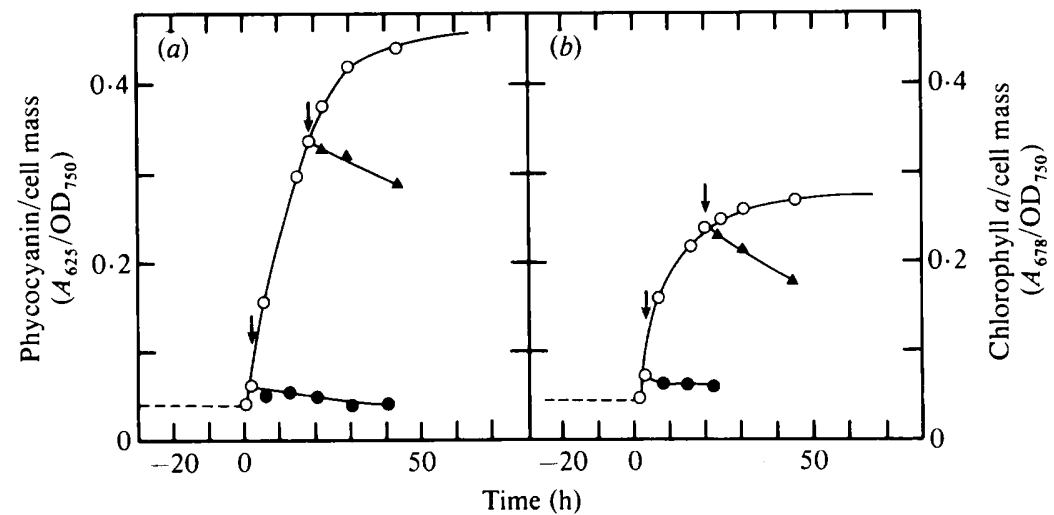

Fig. 4. Effect of streptomycin on antennae acclimation expressed as phycocyanin/cell mass ratio (a) and chlorophyll $a$ /cell mass ratio (b). Symbols as in Fig. 3.

$A_{625} / \mathrm{OD}_{750}$ and $A_{678} / \mathrm{OD}_{750}$ ratios did not decrease to the same extent when streptomycin was added $19 \mathrm{~h}$ after the light shift (Figs 3 and 4). Similar results were also obtained with chloramphenicol and kanamycin $\left(200 \mu \mathrm{g} \mathrm{ml}^{-1}\right)$ (data not shown).

\section{DISCUSSION}

Gendel et al. (1979) used the transcriptional inhibitor rifampicin to study the control of phycoerythrin synthesis during chromatic adaptation in $F$. diplosiphon. We made a similar study on the cyanobacterium $A$. nidulans, which contains only phycocyanin and not phycoerythrin in the rods of the phycobilisomes and which alters its antenna in response to light intensity. We took advantage of the fact that the cellular content of both phycocyanin and chlorophyll $a$ can be measured spectrophotometrically on intact cells. We examined the effect of inhibitors of transcription and translation and showed that phycocyanin and chlorophyll $a$ acclimation are immediately and completely blocked by the two types of inhibitor. Some of the data suggest that the light antennae may exist in an unstable form in the course of the acclimation process.

The spectroscopic method used measures light absorbing chromophore complexes within the bacterial cells. Earlier studies have shown that no free precursor polypeptides of phycoerythrin or phycocyanin can be detected in cells from steady state growth conditions of $F$. diplosiphon and A. nidulans, respectively (Gendel et al., 1979; Yamanaka \& Glazer, 1981). The same was true for $F$. diplosiphon during the adaptation period after a red to green light shift (Gendel et al., 1979). 
Thus, the changes measured in absorption characteristics apparently represent chromophores in the photosynthetic apparatus.

The decrease of phycocyanin and chlorophyll $a$ on addition of the antibiotics 19 or $20 \mathrm{~h}$ after the light shift could reflect either a direct action of the antibiotics on the light-harvesting antennae, an enzymic breakdown of the antennae activated by a block in transcription and/or translation, or a non-enzymic breakdown of the newly synthesized antennae molecules. We believe that the first possibility is unlikely. When we mix purified antennae with the antibiotics, no loss in the corresponding light absorbing units could be seen (data not shown). However, we cannot discriminate between the two other possibilities. It is unlikely, however, that the decrease in $A_{625}$-absorbing units is caused by an active breakdown of phycocyanin since it has been shown that this process requires protein synthesis.

The phycobilisome acclimation response in $A$. nidulans shows differences from the chromatic adaptation response in $F$. diplosiphon (Gendel et al., 1979). Firstly, there is an immediate response (within $20 \mathrm{~min}$ ) to the new light environment in $A$. nidulans while it takes $2 \mathrm{~h}$ for phycoerythrin synthesis to be detected in $F$. diplosiphon. Secondly, we find an immediate block in antenna acclimation after the addition of the drugs while Gendel et al. (1979) found a 1 to $2 \mathrm{~h}$ lag before phycoerythrin synthesis was completely switched off. Unfortunately, Gendel et al. (1979) did not measure chlorophyll $a$ and did not present the acclimation as the ratio of antennae per cell mass. It is therefore not possible from their data to see whether acclimation of chlorophyll $a$ took place or to reveal a breakdown of both antennae such as we observed for $A$. nidulans after the addition of the antibiotics.

Transcriptional and translational inhibitors produced almost identical results on the antennae acclimation of $A$. nidulans. They immediately blocked the acclimation process and phycocyanin and chlorophyll $a$ disappeared at similar rates when the antibiotics were added at a stage where the acclimation process was already quite advanced. However, these results may be expected since both phycocyanobilins, the chromophores of phycocyanin, and chlorophyll $a$ share the same biosynthetic pathways.

The immediate increase in the amount of antennae after an HW-light to LR-light shift as well as the effects of the antibiotics show that regulatory control mechanisms must exist in $A$. nidulans to adjust its photosynthetic apparatus to the new light conditions. The fact that rifampicin halts the acclimation process immediately implies that the control system acts at the transcriptional level. It also shows that no stable RNA species exist that would allow the continued synthesis of both phycocyanin and chlorophyll $a$. The lack of stable messenger RNA for the antennae is supported by the observations of Doolittle (1972) who showed that the mRNA in $A$. nidulans had a restricted stability similar to that in other bacteria.

These studies were supported by Grants B-BU 4629-105 and 269/83 J100:1 from the Swedish Natural Science Research Council and the Swedish Research Council for Forestry and Agriculture, respectively.

\section{REFERENCES}

Bogorad, L. (1975). Phycobiliproteins and complementary chromatic adaptation. Annual Review of Plant Physiology 26, 369-401.

Doolittle, W. F. (1972). Ribosomal ribonucleic acid synthesis and maturation in the blue-green alga Anacystis nidulans. Journal of Bacteriology 111, 316324.

ELEY, J. H. (1971). Effect of carbon dioxide concentration on pigmentation in the blue-green alga Anacystis nidulans. Plant and Cell Physiology 12, 311-316.

GANTT, E. (1979). Structure and function of phycobilisomes: light harvesting pigment complexes in red and blue-green algae. International Review of Cytology 66, 45-80.

Gendel, S., OHAD, I. \& Bogorad, L. (1979). Control of phycoerythrin synthesis during chromatic adaptation. Plant and Cell Physiology 64, 786-790.
Glazer, A. N. (1981). Photosynthetic accessory proteins with bilin prostetic groups. In The Biochemistry of Plants, vol. 8, Photosynthesis, pp. 51-92. Edited by M. D. Hatch \& N. K. Boardman. New York: Academic Press.

Glazer, A. N. (1982). Phycobilisomes: structure and dynamics. Annual Review of Microbiology 36, 173198.

Glazer, A. N., Williams, R. C., Yamanaka, G. \& SCHACHMAN, H. K. (1979). Characterization of cyanobacterial phycobilisomes in zwitterionic detergents. Proceedings of the National Academy of Sciences of the United States of America 76, 61626166.

GoEdHEER, J. C. (1976). Spectral properties of the blue-green alga Anacystis nidulans grown under different environmental conditions. Photosynthetica 10, $411-422$. 
Lundell, D. J., Williams, R. C. \& Glazer, A. N. (1981). Molecular architecture of a light-harvesting antenna. In vitro assembly of the rod substructures of Synechococcus 6301 phycobilisomes. Journal of Biological Chemistry 256, 3580-3592.

LÖNNEBORG, A., Kalla, S. R., LiND, L. K., GuSTAFSSON, P. \& ÖQUIST, G. (1985). Acclimation processes in the light harvesting system of the cyanobacterium Anacystis nidulans during a light shift from white to red light. Plant Physiology 78, 110-114.

Myers, J., Graham, J. \& Wang, R. T. (1978). On spectral control of pigmentation in Anacystis nidulans (Cyanophyceae). Journal of Phycology 14, 513518.

ÖQuIST, G. (1974). Light-induced changes in pigment composition of photosynthetic lamellae and cell-free extracts obtained from the blue-green alga Anacystis nidulans. Physiologia plantarum 30, 45-48.

Raps, S., Wyman, K., Siegelman, H. W. \& FalKowSKI, P. G. (1983). Adaptation of the cyanobacterium Microcystis aeruginosa to light intensity. Plant Physiology 72, 829-832.
RipPKA, R., DeRuelles, J., WATERBURY, J. B., Herdman, M. \& Stanier, R. Y. (1979). Generic assignments, strain histories and properties of pure cultures of cyanobacteria. Journal of General Microbiology 111, 1-61.

SCHNEIDER, W. C. (1945). Phosphorus compounds in animal tissues. I. Extraction and estimation of desoxypentose nucleic acid and pentose nucleic acid. Journal of Biological Chemistry 161, 293-303.

Siva, V., Rao, K., Brand, J. J. \& MYers, J. (1977). Cold shock syndrome in Anacystis nidulans. Plant Physiology 59, 965-969.

Stanier, R. Y. \& Cohen-Bazire, G. (1977). Phototrophic prokaryotes: the cyanobacteria. Annual Review of Microbiology 31, 225-274.

Yamanaka, G. \& Glazer, A. N. (1981). Dynamic aspects of phycobilisome structure: Modulation of phycocyanin content of Synchococcus phycobilisomes. Archives of Microbiology 130, 23-30. 